\title{
openheart Obesity is associated with impaired long-term success of pulmonary vein isolation: a plea for risk factor management before ablation
}

\author{
Gijs E De Maat, ${ }^{1,2}$ Bart Mulder, ${ }^{1}$ Wouter L Berretty, ${ }^{1}$ Meelad I H Al-Jazairi, ${ }^{1}$ \\ Yong E S Tan, ${ }^{1}$ Ans C P Wiesfeld, ${ }^{1}$ Massimo A Mariani, ${ }^{1}$ Isabelle C Van Gelder, ${ }^{1}$ \\ Michiel Rienstra, ${ }^{1}$ Yuri Blaauw ${ }^{1}$
}

To cite: De Maat GE, Mulder B, Berretty WL, et al. Obesity is associated with impaired longterm success of pulmonary vein isolation: a plea for risk factor management before ablation. Open Heart 2018;5:e000771. doi:10.1136/

openhrt-2017-000771

Received 25 December 2017 Revised 13 February 2018 Accepted 6 March 2018

\section{Check for updates}

'Department of Cardiology, University of Groningen, University Medical Center Groningen, Groningen, The Netherlands

${ }^{2}$ Department of Cardio-Thoracic Surgery, University of Groningen, University Medical Center Groningen, Groningen, The Netherlands

Correspondence to Dr Gijs E De Maat; g.e.de. maat@umcg.nl

\section{ABSTRACT}

Aims Obesity is an increasing health problem and is an important risk factor for the development of atrial fibrillation (AF). We investigated the association of body mass index (BMI) on the safety and long-term efficacy of pulmonary vein isolation (PVI) for drug-refractory AF. Methods 414 consecutive patients who underwent transcatheter PVI for AF between 2003 and 2013 were included. Successful PVI was defined as absence of atrial arrhythmia on Holter monitoring or ECG, without and with antiarrhythmic drugs during follow-up. Obesity was defined as $B M l \geq 30 \mathrm{~kg} / \mathrm{m}^{2}$.

Results Mean age was $56 \pm 10$ years, $316(76 \%)$ were male, 311 (75\%) had paroxysmal AF and $111(27 \%)$ were obese. After a mean follow-up of $46 \pm 32$ months (1590 patient-years), freedom from atrial arrhythmia and antiarrhythmic drugs was significantly lower in patients with obesity compared with non-obese patients $(30 \%$ vs $46 \%$, respectively, $P=0.005$, log-rank 0.016 ). With antiarrhythmic drugs, freedom from atrial arrhythmia was $56 \%$ vs $68 \%(P=0.036)$. No differences in minor and major adverse events were observed between patients with obesity and non-obese patients (major $6 \%$ vs $3 \%$, $P=0.105$, and minor $5 \%$ vs $5 \%, P=0.512$ ). Sensitivity analyses demonstrated that $\mathrm{BMI}$ (as continuous variable) was associated with PVI outcome (HR 1.08, 95\% Cl 1.02 to 1.14, $\mathrm{P}=0.012$ )

Conclusion Obesity is associated with reduced efficacy of PVI for drug-refractory AF. No relation between obesity and adverse events was found.

\section{INTRODUCTION}

Transcatheter pulmonary vein isolation (PVI) using radiofrequency energy is a widespread and well-established technique for the treatment of atrial fibrillation (AF). ${ }^{1-3}$ Current guidelines indicate that PVI should be considered even before antiarrhythmic drugs (AADs) have failed in patients with paroxysmal $\mathrm{AF}^{2}$ Catheter ablation is superior to AADs for rhythm control in symptomatic paroxysmal $\mathrm{AF}^{4-6}$ and can also be performed successfully for persistent or long-standing

\section{Key questions}

What is already known about this subject?

- The recent ARREST-AF trial showed that aggressive risk factormanagement improves long-term outcomes of AF ablation. Also, if weight loss issustained at long-term follow-up, reduction of AF burden and maintenance ofsinus rhythm are significantly higher compared to patients with weightfluctuation.

What does this study add?

- This studydemonstrates that obesity isassociated with lower long term success of PVI. Procedural safety was comparable between obese andnonobese patients.

How might this impact on clinical practice?

- Long-termefficacy of PVI seems reduced compared to non-obese patients. Therefore, inobese patients weight loss together with management of other risk factorsshould be considered to reduce AF burden and symptoms, before invasivetreatment modalities are deployed.

persistent $\mathrm{AF}^{7}$ However, radiofrequency PVI has only shown moderate success at long-term follow-up. ${ }^{8-10}$ Several comorbidities increase the risk for $\mathrm{AF}^{11}$ Obesity is an independent risk factor for the development and perpetuation of $\mathrm{AF}^{11}$ and negatively influences success rates of PVI at 1-year follow-up. ${ }^{12}$ The recent ARREST-AF trial showed that aggressive risk factor management improves long-term outcomes of $\mathrm{AF}$ ablation. ${ }^{12}$ Also, if weight loss is sustained at long-term follow-up, reduction of AF burden and maintenance of sinus rhythm are significantly higher compared with patients with weight fluctuation. ${ }^{13}$ The aim of the present study was to investigate long-term outcome in consecutive patients undergoing a PVI 


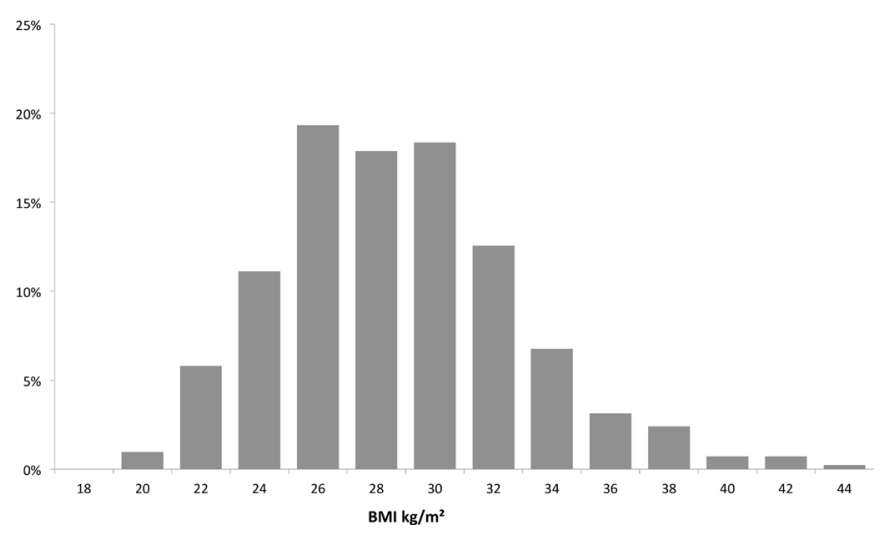

Figure 1 Body mass index (BMI) distribution of the total patient population.

strategy and to assess procedural safety in patients with obesity versus non-obese patients with AF.

\section{METHODS}

\section{Patient population}

We retrospectively analysed all patients scheduled for a first PVI between 2003 and 2013 at the University Medical Center Groningen, the Netherlands. All consecutive patients had highly symptomatic $\mathrm{AF}$ and failed at least one AAD. Exclusion criteria for PVI were significant underlying heart diseases and age $<18$ years or $>80$ years and $<12$ months follow-up. Body mass index (BMI) was determined for all patients at the time of ablation. BMI was calculated by dividing bodyweight in kilograms by the square of the height in metres. Obesity was defined as BMI $\geq 30 \mathrm{~kg} / \mathrm{m}^{2}$. Patients provided informed consent to the ablation procedure. All data were collected following our institutional protocol (see Follow-up section) and concerned standard patient care. Due to the observational nature of the study, no further specific investigation was requested to the patients. Patients' data privacy was granted by coding the database, according to the rules of Good Clinical Practice and Dutch Privacy Law.

\section{Transcatheter radiofreqency PVI strategy}

The transcatheter wide circumferential PVI was performed as described previously. ${ }^{1415}$ During the 10-year study period, the PVI procedure evolved according to technical modifications. Briefly, point-by-point ablation wide antral lines were created around the pulmonary veins. For the first procedures, radiofrequency energy was delivered with a non-irrigated ablation catheter, later on this was an irrigated tip. In the initial patients, PVI was assessed with pacing within the pulmonary veins to conform exit block. From 2011 a circular catheter was used to confirm entrance and exit block. During the first procedure, no additional ablation lines were made. In case the first PVI was unsuccessful, repeat PVI procedures were performed when symptomatic atrial arrhythmias were present $(>3$ months after initial PVI), in consultation with the patient and treating physician. Additional (linear) ablation was performed at the discretion of the treating electrophysiologist.

Following PVI, oral anticoagulation was immediately restarted after the procedure, and low-molecular-weight-heparin was stopped when International Normalized Ratio (INR) $>2.0$ was reached. Oral anticoagulation treatment was given for at least 3 months and thereafter continued based on the $\mathrm{CHADS}_{2}$-score and later on the $\mathrm{CHADS}_{2} \mathrm{VA}_{2} \mathrm{Sc}^{1{ }^{1}}{ }^{2}$ AADs were discontinued after the first three months blanking period if the patient was free from $\mathrm{AF}$ recurrence.

\section{Follow-up}

Patients visited our clinic at 3,6 and 12 months post PVI. Thereafter, patients were seen annually or on indication. To assess the occurrence of (a) symptomatic atrial arrhythmias, at 6 months 48-96-hour Holter monitoring was performed, and at 12 months 24-hour Holter monitoring was performed. At each visit a routine 12-lead ECG was performed, and when atrial arrhythmia was detected, a 12-lead rhythm strip ( $>30$ s) was recorded. In case of symptomatic recurrence without documentation, event recording was performed to confirm and classify the atrial arrhythmia. Follow-up data were censored for patients who reached the primary endpoint or had been followed through 1 December 2015.

\section{Endpoints}

Primary endpoint was freedom of atrial arrhythmias, that is, no evidence of $\mathrm{AF}$, atrial flutter or other atrial arrhythmias with a duration $>30 \mathrm{~s}$, without use of AADs at the end of follow-up. Procedural safety was investigated by reporting the occurrence of periprocedural and procedural minor or major adverse events. Major adverse events were defined as those that resulted in death or permanent injury. Also registered as major adverse events were temporarily injuries that required intervention or specific treatment, (eg, stroke, transient ischaemic attack, major bleeding requiring surgery or blood transfusion or $>2.0$ points haemoglobin decrease, cardiac tamponade and/or perforation, significant or symptomatic pulmonary vein stenosis $>70 \%$, pericarditis and/ or pericardial effusion, myocardial infarction, phrenic nerve lesion, pneumothorax, pneumonia and other not predefined events). Minor adverse events were defined as bleeding from the femoral artery/vein, femoral aneurysm not requiring intervention, pericardial effusion not requiring intervention and asymptomatic pulmonary vein stenosis. ${ }^{16}$

\section{Statistics}

Baseline descriptive statistics are presented as mean $\pm \mathrm{SD}$ or median (range) for continuous variables, if appropriate, and counts with percentages for categorical variables. Differences between subgroups, in terms of patient characteristics at baseline, different follow-up times and end of study, were evaluated by Student's t-test or the MannWhitney $\mathrm{U}$ test, depending on normality of the data. $\chi^{2}$ or 


\begin{tabular}{|c|c|c|c|c|}
\hline & $\begin{array}{l}\text { Total group } \\
\mathrm{N}=414\end{array}$ & $\begin{array}{l}\mathrm{BMI}<30 \\
\mathrm{~N}=303\end{array}$ & $\begin{array}{l}\mathrm{BMI} \geq 30 \\
\mathrm{~N}=111\end{array}$ & $P$ values \\
\hline Age, mean $\pm S D$ (years) & $56 \pm 10$ & $56 \pm 10$ & $56 \pm 10$ & 0.859 \\
\hline Males, n (\%) & $316(76 \%)$ & $236(78 \%)$ & $80(73 \%)$ & 0.298 \\
\hline Chronic heart failure, $\mathrm{n}(\%)$ & $24(6 \%)$ & $13(4 \%)$ & $11(10 \%)$ & 0.034 \\
\hline Diabetes mellitus, n (\%) & $21(5 \%)$ & $12(4 \%)$ & $9(8 \%)$ & 0.124 \\
\hline Previous stroke, $n(\%)$ & $17(4 \%)$ & $11(4 \%)$ & $6(5 \%)$ & 0.407 \\
\hline Hypertension, n (\%) & $213(51 \%)$ & $141(46 \%)$ & $72(65 \%)$ & 0.001 \\
\hline Vascular disease, $\mathrm{n}(\%)$ & $47(11 \%)$ & $36(12 \%)$ & $11(10 \%)$ & 0.726 \\
\hline $\mathrm{CHADS}_{2} \mathrm{VA}_{2} \mathrm{Sc}$ score>1, n (\%) & $142(34 \%)$ & $94(31 \%)$ & $48(43 \%)$ & 0.019 \\
\hline Hypercholesterolaemia, n (\%) & $79(19 \%)$ & $59(19 \%)$ & $20(18 \%)$ & 0.888 \\
\hline Thyroid dysfunction, n (\%) & $35(9 \%)$ & $21(7 \%)$ & $14(13 \%)$ & 0.072 \\
\hline Self-reported OSAS, $n(\%)$ & $13(4 \%)$ & $5(2 \%)$ & $8(7 \%)$ & 0.013 \\
\hline Time since first AF episode, median (IQR) (months) & $63(29-118)$ & $66(30-121)$ & $48(23-108)$ & 0.073 \\
\hline Paroxysmal AF, n (\%) & $311(75 \%)$ & $235(77 \%)$ & $76(68 \%)$ & 0.095 \\
\hline Non-paroxysmal AF, n (\%) & $103(25 \%)$ & $69(23 \%)$ & $34(32 \%)$ & 0.095 \\
\hline LA diameter parasternal, $\mathrm{mm}($ mean $\pm \mathrm{SD})$ & $42 \pm 6$ & $41 \pm 7$ & $44 \pm 5$ & $<0.001$ \\
\hline LVEF, mean $\pm S D$ & $57 \pm 6$ & $58 \pm 5$ & $57 \pm 7$ & 0.234 \\
\hline \multicolumn{5}{|l|}{ AAD use } \\
\hline Class I or III, n (\%) & $275(72 \%)$ & $200(66 \%)$ & $75(68 \%)$ & 0.921 \\
\hline Amiodarone, n (\%) & $93(24 \%)$ & $58(19 \%)$ & $35(32 \%)$ & 0.010 \\
\hline
\end{tabular}

AAD, antiarrhythmic drugs; AF, atrial fibrillation; BMI, body mass index; LVEF, LA left atrial, left ventricular ejection fraction;

OSAS, obstructive sleep apnoea syndrome.

Fisher's exact test was used for comparison of categorical variables. By means of Cox-proportional hazard analyses the association of any increase in BMI with the primary outcome was assessed. Model 1 is adjusted for age and sex, model 2 for age, sex, self-reported obstructive sleep apnoea syndrome (OSAS), previous class I or III AAD use, LA diameter, AF duration, AF type, chronic heart failure and total number of PVI. Model 3 is adjusted for covariates of model 2 and also for the other components of the $\mathrm{CHADS}_{2} \mathrm{VA}_{2} \mathrm{Sc}$, not included in model 2: hypertension, diabetes, vascular disease and stroke. No violations of the proportional hazards assumptions were found. All tests of significance were two-tailed, with $\mathrm{p}$ values $<0.05$ assumed to indicate significance.

\section{RESULTS}

\section{Patient population}

A total of 414 consecutive patients were included in this study. Patient characteristics are shown in table 1 . Mean age was $56 \pm 10$ years. Time since first AF diagnosis was 63 (IQR 29-118) months. AF was paroxysmal in 311 (75\%), mean BMI was $27.8 \pm 4.1 \mathrm{~kg} / \mathrm{m}^{2}$. Among all patients, 111 $(27 \%)$ were obese $\left(\mathrm{BMI} \geq 30 \mathrm{~kg} / \mathrm{m}^{2}\right)$ and $25(6 \%)$ had a $B M I \geq 35 \mathrm{~kg} / \mathrm{m}^{2}$. Distribution of number of patients by BMI is shown in figure 1. Comparing patients with obesity $\left(\mathrm{BMI} \geq 30 \mathrm{~kg} / \mathrm{m}^{2}\right)$ versus non-obese patients $\left(\mathrm{BMI}<30 \mathrm{~kg} / \mathrm{m}^{2}\right)$, several differences were observed: chronic systolic heart failure (left ventricular ejection fraction $(\mathrm{LVEF}) \leq 35 \%$ ), $10 \%$ versus $4 \%, \mathrm{P}=0.034$, hypertension $65 \%$ versus $46 \%, \mathrm{P}=0.001$, self-reported OSAS $7 \%$ versus $2 \%, \mathrm{P}=0.013$. Also left atrial diameter was larger in patients with obesity versus non-obese patients $(44 \pm 5 \mathrm{~mm}$ vs $41 \pm 7 \mathrm{~mm}, \mathrm{P}<0.001$ ).

\section{PVI outcome in the total population}

After a mean follow-up of $46 \pm 32$ months (1590 patientyears; median 37, IQR 19-67), a total of 733 procedures were performed, with a median of 2.0 (range $1-5)$ ablations per patient. Of all patients, $56 \%$ underwent multiple ablation procedures. Overall long-term freedom from atrial arrhythmia and AAD was $42 \%$ (172/414 patients). With AAD this was $65 \%(268 / 414$ patients).

\section{PVI outcome according to obesity}

After a mean follow-up of $46 \pm 32$ months (1590 patientyears), freedom from atrial arrhythmia and AADs was significantly lower in patients with obesity compared with non-obese patients ( $30 \%$ vs $46 \%$, respectively, $\mathrm{P}=0.005$, log-rank 0.016) (table 2 and figure 2). With AADs, freedom from atrial arrhythmia was 56\% versus $68 \%$ $(\mathrm{P}=0.036)$ (table 2).

There was no difference between both groups in median number of procedures $(\mathrm{P}=0.500)$. 


\begin{tabular}{|c|c|c|c|c|}
\hline & Total & $\mathrm{BMI}<30$ & $\mathrm{BMI} \geq \mathbf{3 0}$ & $P$ values \\
\hline Total $\mathrm{n}, \mathrm{PVI}$ median (range) & $2.0(1-5)$ & $2.0(1-4)$ & $2.0(1-5)$ & 0.505 \\
\hline \multicolumn{5}{|l|}{ Multiple procedure success } \\
\hline 12 months FU no AAD, n (\%) & $119(29 \%)$ & $93(31 \%)$ & $26(23 \%)$ & 0.178 \\
\hline 12 months with and without AAD, $n(\%)$ & $221(53 \%)$ & $163(54 \%)$ & $58(52 \%)$ & 0.911 \\
\hline Long-term FU no AAD, n (\%) & $172(42 \%)$ & $139(46 \%)$ & $33(30 \%)$ & 0.005 \\
\hline Long-term FU with and without AAD, $n(\%)$ & $268(65 \%)$ & $206(68 \%)$ & $62(56 \%)$ & 0.036 \\
\hline \multicolumn{5}{|l|}{ Major adverse events } \\
\hline Procedure-related death & 0 & 0 & 0 & \\
\hline Cardiac tamponade/perforation & 9 & 5 & 4 & \\
\hline Thromboembolic event & 4 & 2 & 2 & \\
\hline Air-embolic event & 2 & 2 & 1 & \\
\hline Total (multiple procedures) & $16(4 \%)$ & $9(3 \%)$ & $7(6 \%)$ & 0.105 \\
\hline \multicolumn{5}{|l|}{ Minor adverse events } \\
\hline Femoral bleeding/aneurysm/AVF & 14 & 9 & 5 & \\
\hline Pericardial effusion no intervention & 4 & 3 & 1 & \\
\hline Phrenic nerve lesion & 1 & 1 & 0 & \\
\hline Pulmonary vein stenosis (asymptomatic) & 1 & 1 & 0 & \\
\hline Pericarditis & 1 & 1 & 0 & \\
\hline Total (multiple procedures) & $21(5 \%)$ & $15(5 \%)$ & $6(5 \%)$ & 0.512 \\
\hline Major or minor adverse events (multiple procedures) & $37(9 \%)$ & $24(8 \%)$ & $13(12 \%)$ & 0.158 \\
\hline
\end{tabular}

AAD, antiarrhythmic drugs; AVF, arterial venous fistula; BMI, body mass index; FU, follow-up; PVI, pulmonary vein isolation.

\section{Adverse event according to obesity}

Table 2 shows the periprocedural and procedural minor or major adverse events. In $37(9 \%)$ patients, adverse events occurred, being major in $16(4 \%)$ patients and minor in $21(5 \%)$ patients. There was no in-hospital mortality. No differences in minor and major adverse events were observed between patients with obesity and non-obese patients (major $6 \%$ vs $3 \%, \mathrm{P}=0.105$, and minor $5 \%$ vs $5 \% \mathrm{P}=0.512$, figure 3 ).

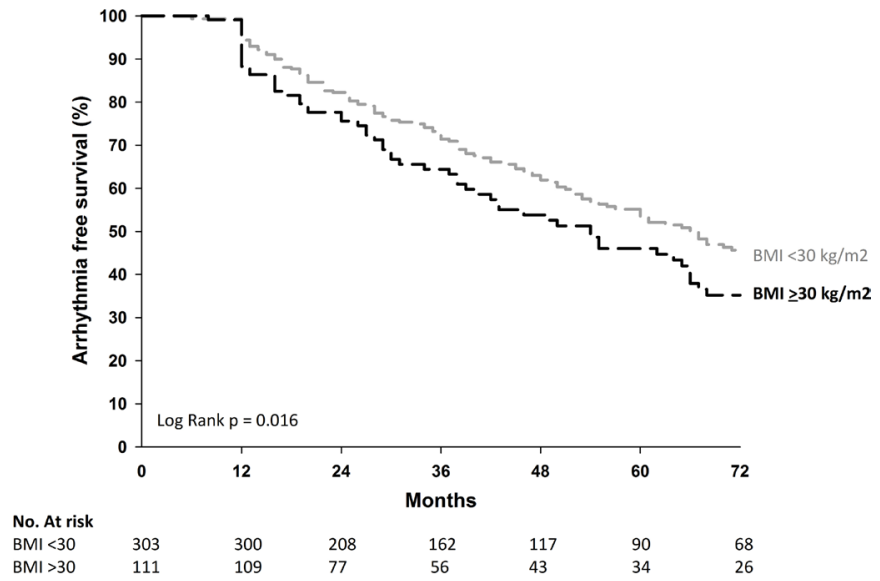

Figure 2 Long-term freedom from atrial arrhythmia and antiarrhythmic drugs for patients with obesity versus nonobese patients following multiple procedures. BMI, body mass index.

\section{Association of BMI and PVI outcome}

As sensitivity analyses, we performed multivariate Cox-proportional hazard analyses and assessed whether an increase in BMI (modelled as continuous covariate) was associated with an increased risk atrial arrhythmia recurrence. No violations of the proportional hazards assumptions were found. Table 3 shows the outcome of different models. When adjusting for the covariates included in model 2, any increase in BMI was associated with failure of PVI with an HR of 1.09 (95\% CI 1.02 to 1.16$), \mathrm{P}=0.039$. Model 3 showed that any increase

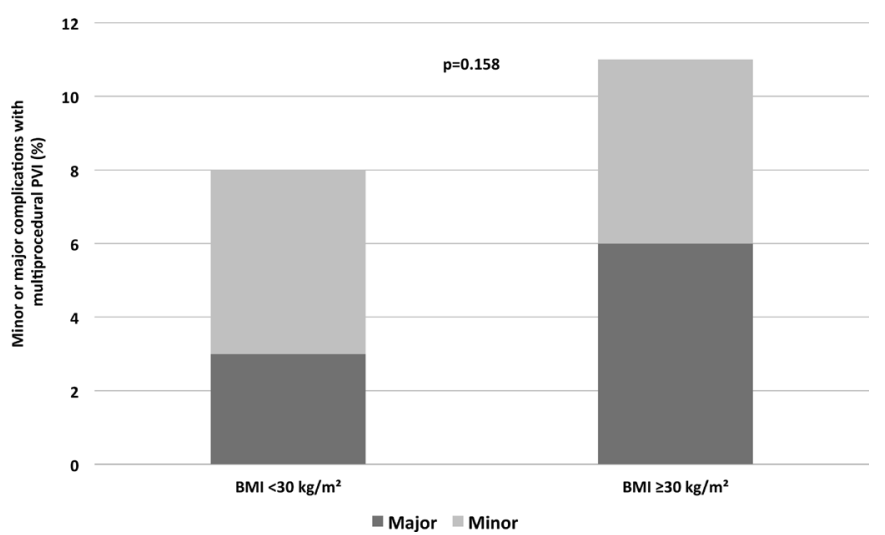

Figure 3 Major and minor adverse events. BMI, body mass index; PVI, pulmonary vein isolation. 
Table 3 Sensitivity analyses of the association of body mass index and long-term outcome after multivariable adjusted analyses

\begin{tabular}{lll}
\hline & HR $(\mathbf{9 5 \%}$ Cl) & P values \\
\hline Model 1 & $1.08(1.02$ to 1.14$)$ & 0.012 \\
Model 2 & $1.09(1.02$ to 1.16$)$ & 0.039 \\
Model 3 & $1.09(1.01$ to 1.16$)$ & 0.017 \\
\hline
\end{tabular}

Model 1 is adjusted for age and sex. Model 2 is adjusted for age, sex, obstructive sleep apnoea syndrome, previous class I or III antiarrhythmic drug use, left atrial diameter, atrial fibrillation duration, atrial fibrillation type, chronic heart failure and total number of pulmonary vein isolation procedures. Model 3 adjusted for all factors mentioned previously and also hypertension, diabetes, vascular disease and stroke.

of BMI was associated with failure of PVI with an HR of 1.09 (95\% CI 1.01 to 1.16$), \mathrm{P}=0.017$.

\section{DISCUSSION}

This retrospective and observational study demonstrates that obesity is associated with lower $>1$-year success of PVI. Procedural safety was comparable between patients with obesity and non-obese patients.

\section{Obesity as cause of AF}

Obesity is an important health problem with an increasing prevalence. There is abundant evidence for the involvement of obesity in the development of AF. Individuals with obesity have up to 2.4-fold increased risk for new-onset AF. ${ }^{17}$ Several mechanisms may underlie the relation between obesity and new-onset AF. It might be related to structural and electrophysiological remodelling caused by elevated end-diastolic pressure, inflammation and increased plasma volume. ${ }^{18}$ Epicardial adipose tissue might cause a paracrine effect, acting through inflammatory markers and adipokines lead to enhanced fibrosis. Fatty infiltration of the atrium can shorten action potential duration. On top of this, local fat depots can cause an arrhythmogenic effect on the atria. In general, obesity is a known cause of hypertension and diabetes, which are both known to promote atrial fibrosis. Animal models of obesity demonstrated increased levels of atrial fibrosis and higher susceptibility and sustainability of AF. In humans, electro-anatomical mapping in patients with obesity showed areas of low voltages indicative of increased atrial fibrosis. ${ }^{18}$ Weight loss has been associated with a decrease of the AF burden in patients. ${ }^{19}$ Also, in human studies cardiac fat quantity has been proven to be related to AF severity and negatively influence ablation results. Following weight reduction, lower levels of inflammatory markers were measured and electro-anatomical mapping demonstrated recovery of atrial voltages. ${ }^{13}$ In our study, hypertension, chronic heart failure and an enlarged atrial size, all parameters associated with a lower success rate of rhythm control, were more frequently present in patients with obesity. ${ }^{3}$ This is in accordance with the literature; the relationship between diastolic impairment and obesity has been established by other groups.

\section{Influence of obesity on PVI outcome}

More and more data become available on obesity and atrial arrhythmia recurrences following PVI. A report of 226 patients with symptomatic, drug-refractory paroxysmal and persistent AF (mean BMI $26.6 \pm 3.5 \mathrm{~kg} / \mathrm{m}^{2}$ ) showed that BMI was not predictive for AF recurrence at a mean follow-up of just over 1 year, although a trend to a higher AF recurrence was found in patients with higher BMI. ${ }^{20}$ Cha et al showed similar results in their study of 523 symptomatic, medication-refractory patients with $\mathrm{AF}$ ( $58 \%$ paroxysmal, $42 \%$ persistent or permanent AF) undergoing PVI. The study showed no difference in success of catheter ablation between the groups of BMI $>25$ (18\%), BMI $25-29.9 \mathrm{~kg} / \mathrm{m}^{2}(44 \%)$ and $\mathrm{BMI} \geq 30$ $(38 \%)$ at $12-24$ months follow-up. ${ }^{21}$ However, the main finding of our study is that we observed a lower success rate of PVI in patients with obesity versus non-obese patients during $>1$-year follow-up. Differences between these studies may be explained by differences in clinical characteristics of the patients and follow-up duration. Of note, we also observed no difference in efficacy during the first year of follow-up, but only after long-term follow-up. The results of the present study seem to be in accordance with the recently published data by Sanders et al, who demonstrated that aggressive risk factor reduction including weight loss improves the outcome of PVI in patients with obesity. ${ }^{12}$ The $>1$-year freedom from atrial arrhythmias in our study is comparable to long-term efficacy rates reported by others. ${ }^{7-9} 22$ Also, the reported adverse events rates are comparable. ${ }^{16}$

\section{Clinical relevance}

Since both obesity and AF pose an epidemic threat, it is important to recognise that $\mathrm{AF}$ is not only more frequent in patients with obesity but also that long-term efficacy of PVI seems reduced compared with non-obese patients. In order to improve long-term results of PVI, patient selection is pivotal. ${ }^{23}$ Therefore, as stated in the new AF guidelines, in patients with obesity, weight loss, together with management of other risk factors, should be considered to reduce AF burden and symptoms before invasive treatment modalities are deployed. ${ }^{3}$ Risk factor modification and weight loss might even result in higher treatment success by reducing substrate and slowing down AF progression.

\section{Strengths and limitations}

Our study was retrospective, precluding definite conclusions about cause-effect relations of obesity and PVI outcome. However, strength of our study was that we had a $>1500$ patient-years follow-up in most patients with extensive Holter recordings, which increased the probability of observing any atrial arrhythmia recurrence. First, short and asymptomatic episodes of AF might be undetected. Second, obesity is often accompanied by more comorbidities, so obesity may reflect a clustering of 
cardiovascular risk factors that may impact PVI outcome, though even after multivariable adjustment the association of BMI with PVI outcome remained. Third, the incidence of OSAS was low and may been caused by the fact we only collected self-reported OSAS, and no structural polysomnography was performed in our cohort. Fourth, the present analysis did not offer the opportunity to look into temporal associations between weight gain of loss and success of PVI. Finally, as described above, the transcatheter ablation strategy evolved over time with the introduction of improved equipment and was applied equally in all patients, regardless of the body mass composition.

\section{CONCLUSION}

Obesity is associated with reduced efficacy of PVI for drug-refractory AF. No relation between obesity and procedural adverse events was found. This emphasise that risk factor reduction before ablation including weight loss should be implemented in the work-up of patients with symptomatic AF referred for AF ablation.

Contributors GedM and BM conducted the analysis. GEdM, BM, MAM and MR wrote the manuscript. YB and IVG designed the study. MIHA-J and WLB assisted in data gathering, processing and statistical analysis. YEST, ACPW, IVG and YB revised the manuscript critically for important intellectual content.

Funding This research received no specific grant from any funding agency in the public, commercial or not-for-profit sectors.

Competing interests None declared.

Patient consent Obtained for the procedure.

Provenance and peer review Not commissioned; externally peer reviewed.

Data sharing statement All available data are reported in the article.

Open Access This is an Open Access article distributed in accordance with the Creative Commons Attribution Non Commercial (CC BY-NC 4.0) license, which permits others to distribute, remix, adapt, build upon this work non-commercially, and license their derivative works on different terms, provided the original work is properly cited and the use is non-commercial. See: http://creativecommons.org/ licenses/by-nc/4.0/

C Article author(s) (or their employer(s) unless otherwise stated in the text of the article) 2018. All rights reserved. No commercial use is permitted unless otherwise expressly granted.

\section{REFERENCES}

1. Camm AJ, Kirchhof P, Lip GY, et al. Guidelines for the management of atrial fibrillation: the task force for the management of atrial fibrillation of the european society of cardiology (ESC). Europace 2010;12:1360-420.

2. Camm AJ, Lip GY, De Caterina R, et al. 2012 focused update of the ESC Guidelines for the management of atrial fibrillation: an update of the 2010 ESC Guidelines for the management of atrial fibrillation-developed with the special contribution of the European Heart Rhythm Association. Europace 2012;14:1385-413.

3. Kirchhof P, Benussi S, Kotecha D, et al. 2016 ESC Guidelines for the management of atrial fibrillation developed in collaboration with EACTS. Eur Heart J 2016;37:2893-962.

4. Calkins H, Kuck KH, Cappato R, et al. 2012 HRS/EHRA/ECAS expert consensus statement on catheter and surgical ablation of atrial fibrillation: recommendations for patient selection, procedural techniques, patient management and follow-up, definitions, endpoints, and research trial design. Europace 2012;14:528-606.

5. Wilber DJ, Pappone C, Neuzil P, et al. Comparison of antiarrhythmic drug therapy and radiofrequency catheter ablation in patients with paroxysmal atrial fibrillation: a randomized controlled trial. JAMA 2010;303:333-40.

6. Morillo CA, Verma A, Connolly SJ, et al. Radiofrequency ablation vs antiarrhythmic drugs as first-line treatment of paroxysmal atrial fibrillation (RAAFT-2): a randomized trial. JAMA 2014;311:692-700.

7. Mont L, Bisbal F, Hernández-Madrid A, et al. Catheter ablation vs. antiarrhythmic drug treatment of persistent atrial fibrillation: a multicentre, randomized, controlled trial (SARA study). Eur Heart $J$ 2014;35:501-7.

8. Ouyang F, Tilz R, Chun J, et al. Long-term results of catheter ablation in paroxysmal atrial fibrillation: lessons from a 5-year follow-up. Circulation 2010;122:2368-77.

9. Tilz RR, Rillig A, Thum AM, et al. Catheter ablation of long-standing persistent atrial fibrillation: 5-year outcomes of the hamburg sequential ablation strategy. J Am Coll Cardiol 2012;60:1921-9.

10. Weerasooriya R, Khairy P, Litalien J, et al. Catheter ablation for atrial fibrillation: are results maintained at 5 years of follow-up? J Am Coll Cardiol 2011;57:160-6.

11. Vermond RA, Geelhoed B, Verweij N, et al. Incidence of atrial fibrillation and relationship with cardiovascular events, heart failure, and mortality: a community-based study from the Netherlands. J Am Coll Cardiol 2015;66:1000-7.

12. Pathak RK, Middeldorp ME, Lau DH, et al. Aggressive risk factor reduction study for atrial fibrillation and implications for the outcome of ablation: the ARREST-AF cohort study. J Am Coll Cardiol 2014;64:2222-31.

13. Pathak RK, Middeldorp ME, Meredith M, et al. Long-term effect of goal-directed weight management in an atrial fibrillation cohort: a long-term follow-up study (LEGACY). J Am Coll Cardiol 2015;65:2159-69.

14. De Maat GE, Van Gelder IC, Rienstra M, et al. Surgical vs. transcatheter pulmonary vein isolation as first invasive treatment in patients with atrial fibrillation: a matched group comparison. Europace 2014;16:33-9.

15. Tan ES, Mulder BA, Rienstra M, et al. Pulmonary vein isolation of symptomatic refractory paroxysmal and persistent atrial fibrillation: a single centre and single operator experience in the Netherlands. Neth Heart J 2009;17:366-72.

16. Cappato R, Calkins H, Chen SA, et al. Updated worldwide survey on the methods, efficacy, and safety of catheter ablation for human atrial fibrillation. Circ Arrhythm Electrophysiol 2010;3:32-8.

17. Frost L, Hune LJ, Vestergaard P. Overweight and obesity as risk factors for atrial fibrillation or flutter: the Danish Diet, Cancer, and Health Study. Am J Med 2005;118:489-95.

18. Nalliah CJ, Sanders P, Kottkamp H, et al. The role of obesity in atrial fibrillation. Eur Heart J 2016;37.

19. Pathak RK, Elliott A, Middeldorp ME, et al. Impact of CARDIOrespiratory FITness on arrhythmia recurrence in obese individuals with atrial fibrillation: The CARDIO-FIT Study. J Am Coll Cardiol 2015;66:985-96.

20. Letsas KP, Siklódy CH, Korantzopoulos P, et al. The impact of body mass index on the efficacy and safety of catheter ablation of atrial fibrillation. Int J Cardiol 2013;164:94-8.

21. Cha YM, Friedman PA, Asirvatham SJ, et al. Catheter ablation for atrial fibrillation in patients with obesity. Circulation 2008;117:2583-90.

22. Teunissen C, Kassenberg W, van der Heijden JF, et al. Five-year efficacy of pulmonary vein antrum isolation as a primary ablation strategy for atrial fibrillation: a single-centre cohort study. Europace 2016;18:1335-42.

23. Gorenek B, Pelliccia A, Benjamin EJ, et al. European Heart Rhythm Association (EHRA)/European Association of Cardiovascular Prevention and Rehabilitation (EACPR) position paper on how to prevent atrial fibrillation endorsed by the Heart Rhythm Society (HRS) and Asia Pacific Heart Rhythm Society (APHRS). Europace 2016;19:190-225. 


\section{Correction: Obesity is associated with impaired long-term success of pulmonary vein isolation: a plea for risk factor management before ablation}

De Maat GE, Mulder B, Berretty WL, et al. Obesity is associated with impaired longterm success of pulmonary vein isolation: a plea for risk factor management before ablation. Open Heart 2018;5:e000771.

Two of the co-authors' names have been spelled incorrectly in this article. The correct names are Bart A Mulder and Eng-Shiong Tan.

Open access This is an open access article distributed in accordance with the Creative Commons Attribution Non Commercial (CC BY-NC 4.0) license, which permits others to distribute, remix, adapt, build upon this work non-commercially, and license their derivative works on different terms, provided the original work is properly cited, appropriate credit is given, any changes made indicated, and the use is non-commercial. See:http://creativecommons.org/licenses/by-nc/4.0/.

Open Heart 2018;5:e000771corr1. doi:10.1136/openhrt-2017-000771corr1

A) Check for updates 